\title{
Dynamic Evaluation of the Contractile Function of Lumbodorsal Muscles During the Locust Pose in Yoga by Real-Time Ultrasound
}

\author{
Wenfen Liu \\ Jiachun Li \\ The Seventh Affiliated Hospital Sun Yat-sen University \\ xiang zhou \\ Sun Yat-sen University First Affiliated Hospital

\section{Ningning Chen} \\ The Seventh Affiliated Hospital Sun Yat-sen University \\ Hui Ouyang \\ The Seventh Affiliated Hospital Sun Yat-sen University

\section{Zuofeng Xu} \\ The Seventh Affiliated Hospital Sun Yat-sen University \\ Yongsheng Zhu ( $\sim 1946295663 @ q q . c o m$ ) \\ Shenzhen Hospital of Southern Medical University
}

The Seventh Affiliated Hospital Sun Yat-sen University https://orcid.org/0000-0001-9402-1723

\section{Research article}

Keywords: Low back pain, lumbodorsal muscles, muscle thickness, locust yoga pose, ultrasonography

Posted Date: December 22nd, 2020

DOI: https://doi.org/10.21203/rs.3.rs-131704/v1

License: (9) (i) This work is licensed under a Creative Commons Attribution 4.0 International License. Read Full License

Version of Record: A version of this preprint was published at BMC Sports Science, Medicine and Rehabilitation on August 10th, 2021. See the published version at https://doi.org/10.1186/s13102-021-00313-0. 


\section{Abstract}

Background and Purpose: The purpose was to observe the changes in the thickness of lumbodorsal muscles that occur during the locust pose in yoga and how these changes occur. From the changes in muscle thickness that occur in the locust pose, the contractile function of lumbodorsal muscles can be evaluated.

Methods: The changes in the thickness of the lumbodorsal muscles in the relaxed and contracted states were dynamically observed by real-time ultrasound when subjects were performing the locust yoga pose. Then, the thicknesses of the muscles during the two states were measured to calculate the ratio of contraction of each muscle and determine the statistical significance of the change in thickness of each muscle.

Results: The mean thicknesses of the lumbodorsal muscles, including the multifidus, longissimus, iliocostalis, and quadratus lumborum, obviously differed between the relaxed and contracted states $(P<0.005)$. The the mean $C / R$ of the longissimus was $1.39 \pm 0.14$ on the left and $1.40 \pm 0.16$ on the right. The multifidus and iliocostalis had the second highest $C / R$. The mean $C / R$ of the multifidus was $1.23 \pm 0.12$ on the left and $1.24 \pm 0.15$ on the right, and the mean $\mathrm{C} / \mathrm{R}$ of the iliocostalis was $1.25 \pm 0.12$ on the left and $1.24 \pm 0.14$ on the right. The quadratus lumborum had the lowest $C / R$, and the mean $C / R$ of the quadratus lumborum was $1.17 \pm 0.10$ on the left and $1.19 \pm 0.11$ on the right.

Conclusions: The contractile activity of the lumbar muscles can be observed by ultrasound to evaluate the contractile function of the lumbar muscles.

\section{Background}

Low back pain (LBP) is defined as pain and discomfort localized above the inferior gluteal folds and below the costal margin, regardless of whether leg pain is involved. Chronic LBP is defined as a minimum of 12 weeks of LBP unless otherwise specified(1). In 1987, Waddell indicated that the prevalence rate of LBP was as high as $80 \%$. He introduced three categories of chronic LBP, which have become internationally accepted: 1. specific spinal pathology; 2 . nerve root pain/radicular pain; and 3. nonspecific LBP(2).

Despite the very high prevalence of LBP, its pathophysiology is poorly understood, and no associations between investigative findings and clinical symptoms have been found(3). Although the cause of LBP is obscure, systematic literature reviews have indicated that physical exercises are effective in reducing pain and disability in patients suffering from $\operatorname{LBP}(4,5)$.

The European guidelines released in 2006 recommend supervised exercise therapy as a first-line treatment in the management of chronic LBP. Previous research has failed to show that one type of exercise program is superior to another. Existing research has clearly demonstrated that regardless of the type of exercise, exercise therapy is effective in alleviating pain and dysfunction. The type of exercise is selected according to the patient's and therapist's preferences and the specific situation $(1,6)$. However, the mechanism by which exercise therapy relieves pain and dysfunction cannot be explained by existing research. Does exercise yield significant changes in the lumbar muscle? Which muscle groups are most affected by a particular type of exercise? Are certain imaging methods appropriate for specific evaluations? To date, there has not been a way to quantify the effectiveness of different kinds of exercise, that is whether a particular type of exercise is effective, other than by the patient's chief complaint, which is often subjective; thus, we need to identify a way to objectively assess exercise effectiveness.

The lumbodorsal muscles are mainly composed of the multifidus, longissimus, iliocostalis and quadratus lumborum. Magnetic resonance imaging (MRI) is considered the standard method of imaging for the assessment of posterior trunk muscles. MRI can provide clear images of not only anatomical structures but also boundaries of different tissues. However, the long waiting time for an appointment, long examination time and high examination cost limit its use in routine clinical applications $(7,8)$. Ultrasonography (US) advanced rapidly over the past 50 years, and it is widely used in the clinic in fields such as gynecology and obstetrics and other fields in which abdominal and superficial organs, cardiovascular structures, and especially, musculoskeletal structures are examined $(9,10)$. For instance, US has been used to directly assess atrophy and hypertrophy in different muscles $(11,12)$. Although the image resolution of CT and MRI is higher than that of US, US imaging has obvious advantages 
over other imaging techniques: it is noninvasive, does not use radiation, can be used to acquire images in multiple planes, has low examination costs, and most importantly, can dynamically assess the shrinkage of lumbodorsal muscles during contractions and relaxation in real time, which cannot be achieved by $\operatorname{MRI}(7,12)$.

Muscle thickness often increases by varying degrees as it contracts. Existing studies have reported that ultrasonography can be used to observe changes in the thickness of muscles, except for lumbodorsal muscles, during contractions and relaxation to detect or measure muscle "activity"(13-16). However, currently, there is no uniform, simple, feasible method for assessing lumbodorsal muscle activity.

Yoga originated in ancient India(17), and it has been widely accepted by clinicians and patients with LBP(18-25). We chose the locust yoga pose (Fig. 1) as the contracted state and prone position as the resting state. The main purposes of this study were to use real-time ultrasound to observe the changes in the thicknesses of lumbodorsal muscles dynamically in contracted and relaxed states, to determine which muscle has the highest contraction ratio of change, and to determine whether ultrasound can be effective for examining the lumbar muscle.

\section{Methods}

A total of 52 healthy volunteers were recruited. All participants were between the ages of 19 and 68 . Participants were eliminated if they had current or chronic LBP, a history of back surgery, or a serious spinal pathology, such as fracture, cancer, or infection. Each eligible participant was informed of all experimental procedures and provided informed written consent. In addition, information about their height and weight was obtained before the examination.

All subjects were trained to master the completely relaxed state and the posture of the locust yoga pose. For the relaxed state, subjects laid flat on the examination bed in the prone position, with both of their arms resting naturally to the sides of their body, their head slightly resting to one side, and their legs relaxed. For the locust pose, participants laid in a prone position, with their hands pronated, shoulder blades retracted together, gaze looking forward and downward, shoulder and elbows extended, spine extended, lower abdomen in contact with the bed surface to act as a fulcrum, hips and legs extended, and feet plantarflexed; both the angle between the lower limbs and the bed surface and the angle between the trunk and the bed surface were maintained to be as close to $30^{\circ}$ as possible. The whole body was bent like an inverted arch (Fig. 1).

In the relaxed state, the probe was placed transverse at the upper waist, and the 1st lumbar vertebra was identified according to the 12th rib. Then, the probe was gradually moved downward to observe the general shape of the cross-sections of each lumbodorsal muscle. At the level of the 4 th lumbar vertebra, the probe was rotated $90^{\circ}$ clockwise to view a section of each muscle in the sagittal plane. The transducer was oriented in the sagittal plane so that it was parallel to the muscle fibers to the greatest extent possible(26). The muscles were measured in the sagittal plane. Each muscle was measured as vertically as possible along the long axis of the muscle fibers to reduce measurement errors due to angulation. All eight muscles on both sides of the lower back were measured sequentially, from the shallow to the deep, from the middle to the side, first left then right. The order was as follows: the multifidus, the quadratus lumborum, the longissimus and the iliocostalis.

Each subject was in a relaxed state when the optimal sagittal section of each muscle was recorded to ensure that the probe position did not change, and then, the subject was asked to perform the locust yoga pose. To record the optimal sagittal section of each muscle during the contracted state, still images were unified with the double mode(27), and still images in the left diastolic and right contracted states were assessed. The thickness of all the muscles in different positions was measured three times, and then, on the other contraction image, in the same position, the thickness was also measured three times. Finally, the average of the measurements was recorded.

All examinations and measurements were performed by two sonographers with more than 10 years of ultrasound experience. All data analyses were performed using SPSS statistical software (v.20.0; IBM Corp., Armonk, NY). All data followed a normal distribution. One-way ANOVA was used to compare the differences between the two groups of data (pre-exercise and exercise motion), and the relationship between each of them was also analyzed. The $p$ value of less than 0.05 was considered significant. 


\section{Results}

Table 1

The mean thicknesses of four muscles in the relaxed and contracted states (Unit: centimeter), the related $\mathrm{C} / \mathrm{R}$ ratio, and the $\mathrm{p}$ value in differences between the relaxed and contracted states for the four muscles

\begin{tabular}{|c|c|c|c|c|c|c|c|c|}
\hline & $\begin{array}{l}\text { the left } \\
\text { multifidus }\end{array}$ & $\begin{array}{l}\text { the right } \\
\text { multifidus }\end{array}$ & $\begin{array}{l}\text { the left } \\
\text { quadratus } \\
\text { lumborum }\end{array}$ & $\begin{array}{l}\text { the right } \\
\text { quadratus } \\
\text { lumborum }\end{array}$ & $\begin{array}{l}\text { the left } \\
\text { longissimus }\end{array}$ & $\begin{array}{l}\text { the right } \\
\text { longissimus }\end{array}$ & $\begin{array}{l}\text { the left } \\
\text { iliocostalis }\end{array}$ & $\begin{array}{l}\text { the right } \\
\text { iliocostalis }\end{array}$ \\
\hline $\begin{array}{l}\text { Resting } \\
\text { state }\end{array}$ & $\begin{array}{l}1.32 \pm \\
0.27\end{array}$ & $\begin{array}{l}1.37 \pm \\
0.31\end{array}$ & $\begin{array}{l}1.38 \pm \\
0.32\end{array}$ & $\begin{array}{l}1.30 \pm \\
0.32\end{array}$ & $2.33 \pm 0.51$ & $2.34 \pm 0.49$ & $\begin{array}{l}1.88 \pm \\
0.41\end{array}$ & $\begin{array}{l}1.98 \pm \\
0.40\end{array}$ \\
\hline $\begin{array}{l}\text { Contracted } \\
\text { state }\end{array}$ & $\begin{array}{l}1.60 \pm \\
0.30\end{array}$ & $\begin{array}{l}1.68 \pm \\
0.38\end{array}$ & $\begin{array}{l}1.62 \pm \\
0.40\end{array}$ & $\begin{array}{l}1.55 \pm \\
0.41\end{array}$ & $3.20 \pm 0.61$ & $3.26 \pm 0.68$ & $\begin{array}{l}2.34 \pm \\
0.49\end{array}$ & $\begin{array}{l}2.44 \pm \\
0.56\end{array}$ \\
\hline $\mathrm{C} / \mathrm{R}$ & $\begin{array}{l}1.23 \pm \\
0.12\end{array}$ & $\begin{array}{l}1.24 \pm \\
0.15\end{array}$ & $\begin{array}{l}1.17 \pm \\
0.10\end{array}$ & $\begin{array}{l}1.19 \pm \\
0.11\end{array}$ & $1.39 \pm 0.14$ & $1.40 \pm 0.16$ & $\begin{array}{l}1.25 \pm \\
0.12\end{array}$ & $\begin{array}{l}1.24 \pm \\
0.14\end{array}$ \\
\hline $\mathrm{F}$ & 26.49 & 21.14 & 10.71 & 11.54 & 62.17 & 62.11 & 26.34 & 23.63 \\
\hline$P$ & $<0.001$ & $<0.001$ & $=0.001$ & $=0.001$ & $<0.001$ & $<0.001$ & $<0.001$ & $<0.001$ \\
\hline
\end{tabular}

In this study, 52 individuals met the inclusion criteria, including 31 women and 21 men aged 18 to 68 years; the mean age was $40.35 \pm 11.042$ years, and the mean body mass index (BMI) was $23.845 \pm 3.476$. Clear ultrasound images were captured for all the volunteers.

The thickness of the muscles, including the multifidus, longissimus, iliocostalis, and quadratus lumborum, in relaxed and contracted states, were measured. The mean thicknesses of these muscles in the relaxed and contracted states are shown in Table 1. The thickness in the contracted state divided by that in relaxed state is denoted by $C / R$, and the mean $C / R$ for each muscle is also shown in Table 1. Among these four muscles, the longissimus had the highest $C / R$, and the mean $C / R$ was $1.39 \pm$ 0.14 on the left and $1.40 \pm 0.16$ on the right. The multifidus and iliocostalis had the second highest $\mathrm{C} / \mathrm{R}$. The mean $\mathrm{C} / \mathrm{R}$ of the multifidus was $1.23 \pm 0.12$ on the left and $1.24 \pm 0.15$ on the right, and the mean $C / R$ of the iliocostalis was $1.25 \pm 0.12$ on the left and $1.24 \pm 0.14$ on the right. The quadratus lumborum had the lowest $C / R$, and the mean $C / R$ of the quadratus lumborum was $1.17 \pm 0.10$ on the left and $1.19 \pm 0.11$ on the right. The differences between the relaxed and contracted states for all the muscles had a p value of less than 0.005 (Fig. 2). Figure 2 to 5 show different muscles in the relaxed and contracted states. The blue line indicates the thickness of the muscle in the relaxed state. The red line indicates the thickness of the muscle in the contracted state.

\section{Discussion}

In the past, researchers studying LBP have comprehensively assessed the vertebrae, discs, and intervertebral joints of the back. Nevertheless, the importance of the lumbodorsal muscles in stabilizing the lumbar spine should not be underestimated(28, 29), and this viewpoint was excellently illustrated in a study that provided quantitative data about the stabilizing effects of muscles with regard to the mechanics of the spine $(29,30)$. Therefore, in this study, we focused on the changes in the back muscles of patients with LBP.

Previous studies have shown that the lumbar muscles often degenerate by different degrees when patients suffer from LBP(31, 32). This degeneration manifests as decreases in the cross-sectional areas (CSAs) of muscles(31, 33-37), increases in fat content(32, 38-40) and changes in the proportions of muscle fiber types (more type II fibers, fewer type I fibers)(41). Although the above structural changes of the paraspinal muscles have been reported frequently in the existing literature, there is no consistent conclusion on the changes in muscle morphology and structure in LBP patients, and many of the results are inconsistent. This inconsistency is probably due to different etiologies leading to different pathological changes, such as fatty infiltration itself, which increases muscle thickness. Moreover, there are many other related factors; for instance, the pathology of the same disease varies at different stages(42). On the other hand, other studies have confirmed that pain is not associated with structural changes in paraspinal muscles(43-47). 
Changes in structure may lead to changes in muscle fiber elasticity, which inevitably affect muscle function. Even without changes in muscle structure, pain causes pain-related nerve suppression, and the level of activity of lumbar muscles decreases to prevent tissue damage(48), thereby affecting muscle contractile function. Therefore, it can be assumed that patients with LBP exhibit changes in muscle contractile function to a certain extent, regardless of whether there are morphological structural changes or how the structure changes.

As actin and myosin filaments overlap more during muscle contractions than during relaxation, the muscle generally becomes thicker and shorter $(49,50)$. Real-time ultrasound can be used to observe dynamic changes in muscle thickness from relaxed to contracted states. The contraction ratio can be calculated according to the muscle thickness in the two different states to quantitatively evaluate muscle contractile function $(51,52)$.

In the existing literature on lumbodorsal muscles, the posture in which patients were examined differed among studies. Some evaluations were performed in an upright position, while others were performed in a prone or supine position. In the supine position, which is often used for MRI and CT scans, the back muscles are often compressed and deformed due to the patient's body weight. In the upright position, the human body needs small levels of muscular activity to maintain the pose, which might affect the thicknesses of lumbar muscles(42). Furthermore, in the standing and supine positions, it is difficult to observe and measure changes in lumbodorsal muscles with US. Therefore, the prone position was chosen for our study. With subjects in the prone position, we can ensure that there are no additional contractions of the muscles in the relaxed state, and it is convenient for taking measurements.

Yoga has been widely accepted by clinicians and patients with LBP(18-25). However, yoga contains a variety of postures(18, 53), and we assume that each posture targets different muscles. According to our experience in clinical practice, the locust yoga pose is an effective exercise to relieve LBP. We chose the locust yoga pose as the contracted state because of the following three primary reasons. First, the locust yoga pose is effective in relieving LBP. Second, the action is simple and easy to perform. Third, it is convenient for us to observe and measure muscles during this pose.

In our study, the data objectively showed that the locust yoga pose can be used to exercise the lumbar back muscles, especially the longissimus. Therefore, the movement can be prescribed for patients with LBP. According to the measurements of the thickness of lumbodorsal muscles taken in a uniform manner during the locust pose, the contraction ratio of each muscle (C/R) was calculated to uniformly quantify the contraction function of each muscle.

However, our study has some limitations. First, yoga involves various poses; in this study, we investigated only the locust pose. Second, the sample size was relatively small, so a study with a larger sample size needs to be conducted to determine the normal range of the contraction ratio of each muscle. Third, the subjects of this study were normal people without LBP. Some patients may not be able to perform the exercise mentioned above and therefore may not be eligible for future studies including patients with LBP.

\section{Conclusion}

The locust pose in yoga can be used to exercise the lumbar muscle group. The contractile activity of the lumbar muscles can be observed by ultrasound to evaluate the contractile function of the lumbar muscles.

\section{Abbreviations}

BMI (body mass index), C/R (Contracted state/ Resting state), CSAs (cross-sectional areas), LBP (Low back pain), MRI (Magnetic resonance imaging), US (Ultrasonography)

\section{Declarations}

\section{Ethics approval and consent to participate}


The study was approved by the Ethics Committees of the Seventh Affiliated Hospital of Sun Yat-sen University. All procedures were carried out in accordance with ethical standards. Written informed consent was obtained from all individual participants included in the study.

\section{Consent for publication}

All participants, including those depicted in Figure 1, gave written and informed consent for publication for all personal or clinical details along with any identifying images to be published in this study.

\section{Availability of data and material}

The datasets used or analysed during the current study are available from the corresponding author on reasonable request.

\section{Competing interests}

The authors have no conflicts of interest to declare.

\section{Funding}

This study was funded by the Seventh Affiliated Hospital of SYSU, Clinical Research Fund (ZSQYLCKYJJ202018). The funders have had no role in the design of the study nor will they have any role in the collection, analysis and interpretation of the data and in the writing of the manuscript.

\section{Authors' contributions}

$\mathrm{WL}, \mathrm{YZ}$ and $\mathrm{ZX}$ conceived of the presented idea.

WL and ZX performed the ultrasound testing.

$\mathrm{WL}$ and $\mathrm{JL}$ to the analysis of the results and to the writing of the manuscript.

$\mathrm{XZ}, \mathrm{NC}$ and $\mathrm{HO}$ performed the calculations and statistical data.

All authors discussed the results and contributed to the final version of the manuscript.

\section{Acknowledgements}

We wish to thank Jie Li and Danni He as the model for picture.

\section{References}

1. AIRAKSINEN O, BROX JI. CEDRASCHI C, et al. Chapter 4. European guidelines for the management of chronic nonspecific low back pain. EUR SPINE J. 2006;15(Suppl 2):192-300.

2. WADDELL G. 1987 Volvo award in clinical sciences. A new clinical model for the treatment of low-back pain. Spine (Phila Pa 1976). 1987;12:632 - 44.

3. KADER DF, SMITH WARDLAWD. FW. Correlation between the MRI changes in the lumbar multifidus muscles and leg pain. CLIN RADIOL. 2000;55:145-49.

4. SMIDT N, de VET HC, BOUTER LM, et al. Effectiveness of exercise therapy: a best-evidence summary of systematic reviews. Aust J Physiother. 2005;51:71-85.

5. BOUCHER JA, PREUSS R, HENRY SM, DUMAS JP. LARIVIERE C. The effects of an 8-week stabilization exercise program on lumbar movement sense in patients with low back pain. BMC Musculoskelet Disord. 2016;17:23.

6. HAYDEN JA, van TULDER MW TOMLINSONG. Systematic review: strategies for using exercise therapy to improve outcomes in chronic low back pain. ANN INTERN MED. 2005;142:776-85. 
7. SIONS JM, TEYHEN DS. HICKS GE. Criterion Validity of Ultrasound Imaging: Assessment of Multifidi Cross-Sectional Area in Older Adults With and Without Chronic Low Back Pain. J GERIATR PHYS THER. 2017;40:74-9.

8. PARKKOLA R, RYTOKOSKI U. KORMANO M. Magnetic resonance imaging of the discs and trunk muscles in patients with chronic low back pain and healthy control subjects. Spine (Phila Pa 1976). 1993;18:830-36.

9. HARCKE HT, GRISSOM LE. FINKELSTEIN MS. Evaluation of the musculoskeletal system with sonography. AJR Am J Roentgenol. 1988;150:1253-61.

10. KAPLAN PA, MATAMOROS AJ, ANDERSON JC. Sonography of the musculoskeletal system. AJR Am J Roentgenol. 1990;155:237-45.

11. HIDES JA, STOKES MJ, SAIDE M, JULL GA, COOPER DH. Evidence of lumbar multifidus muscle wasting ipsilateral to symptoms in patients with acute/subacute low back pain. Spine (Phila Pa 1976). 1994;19:165-72.

12. GHAMKHAR L, EMAMI M, MOHSENI-BANDPEI MA BEHTASHH. Application of rehabilitative ultrasound in the assessment of low back pain: a literature review. J Bodyw Mov Ther. 2011;15:465-77.

13. HODGES PW, PENGEL LH, HERBERT RD, GANDEVIA SC. Measurement of muscle contraction with ultrasound imaging. MUSCLE NERVE. 2003;27:682-92.

14. CRITCHLEY D. Instructing pelvic floor contraction facilitates transversus abdominis thickness increase during lowabdominal hollowing. Physiother Res Int. 2002;7:65-75.

15. MISURI G, COLAGRANDE S, GORINI M, et al. In vivo ultrasound assessment of respiratory function of abdominal muscles in normal subjects. EUR RESPIR J. 1997;10:2861-67.

16. YOUNG A, STOKES M. CROWE M. Size and strength of the quadriceps muscles of old and young women. EUR J CLIN INVEST. 1984;14:282-87.

17. ZENG JIE GAO JYCY. Prone positioned upside done arch exercise, a kind of lumbodorsal muscles training, curbs the progression of lumbar disc bulge. TMR Non-Drug Therapy. 2018;1(1):9-15.

18. SAPER RB, SHERMAN KJ, CULLUM-DUGAN D, DAVIS RB, PHILLIPS RS. CULPEPPER L. Yoga for chronic low back pain in a predominantly minority population: a pilot randomized controlled trial. Altern Ther Health Med. 2009;15:18-27.

19. TILBROOK HE, COX H, HEWITT CE, et al. Yoga for chronic low back pain: a randomized trial. ANN INTERN MED. 2011;155:569-78.

20. SARAGIOTTO BT, YAMATO TP. MAHER C. Yoga for low back pain: PEDro systematic review update. Br J Sports Med. 2015;49:1351.

21. CHANG DG KERTESZSG. Yoga and Low Back Pain: No Fool's Tool. ANN INTERN MED. 2017;167:129-30.

22. GROESSL EJ, LIU L, CHANG DG, et al. Yoga for Military Veterans with Chronic Low Back Pain: A Randomized Clinical Trial. AM J PREV MED. 2017;53:599-608.

23. SAPER RB, LEMASTER C, DELITTO A, et al. Yoga, Physical Therapy, or Education for Chronic Low Back Pain: A Randomized Noninferiority Trial. ANN INTERN MED. 2017;167:85-94.

24. MUNK R. Yoga classes may be an alternative to physiotherapy for people with chronic nonspecific low back pain [commentary]. J PHYSIOTHER. 2018;64:57.

25. GROTLE M, HAGEN KB. Yoga classes may be an alternative to physiotherapy for people with chronic nonspecific low back pain [synopsis]. J PHYSIOTHER. 2018;64:57.

26. CREZE M, NYANGOH TK, GAGEY O, BELLIN MF ROCHERL. SOUBEYRAND M. Feasibility assessment of shear wave elastography to lumbar back muscles: A Radioanatomic Study. CLIN ANAT. 2017;30:774-80.

27. SIONS JM, VELASCO TO, TEYHEN DS. HICKS GE. Reliability of ultrasound imaging for the assessment of lumbar multifidi thickness in older adults with chronic low back pain. J GERIATR PHYS THER. 2015;38:33-9.

28. CHOLEWICKI J, MCGILL SM. Mechanical stability of the in vivo lumbar spine: implications for injury and chronic low back pain. Clin Biomech (Bristol Avon). 1996;11:1-15.

29. DANNEELS LA, VANDERSTRAETEN GG, CAMBIER DC, WITVROUW EE, De CUYPERHJ. CT imaging of trunk muscles in chronic low back pain patients and healthy control subjects. EUR SPINE J. 2000;9:266-72. 
30. GOEL VK, KONG W, HAN JS, WEINSTEIN JN. GILBERTSON LG. A combined finite element and optimization investigation of lumbar spine mechanics with and without muscles. Spine (Phila Pa 1976). 1993;18:1531-41.

31. DANNEELS LA, VANDERSTRAETEN GG, CAMBIER DC, WITVROUW EE, De CUYPERHJ. CT imaging of trunk muscles in chronic low back pain patients and healthy control subjects. EUR SPINE J. 2000;9:266-72.

32. PARKKOLA R, RYTOKOSKI U. KORMANO M. Magnetic resonance imaging of the discs and trunk muscles in patients with chronic low back pain and healthy control subjects. Spine (Phila Pa 1976). 1993;18:830-36.

33. HIDES JA, STOKES MJ, SAIDE M, JULL GA, COOPER DH. Evidence of lumbar multifidus muscle wasting ipsilateral to symptoms in patients with acute/subacute low back pain. Spine (Phila Pa 1976). 1994;19:165-72.

34. HIDES J, GILMORE C, STANTON W. BOHLSCHEID E. Multifidus size and symmetry among chronic LBP and healthy asymptomatic subjects. Man Ther. 2008;13:43-9.

35. FORTIN M. MACEDO LG. Multifidus and paraspinal muscle group cross-sectional areas of patients with low back pain and control patients: a systematic review with a focus on blinding. PHYS THER. 2013;93:873-88.

36. PLOUMIS A, MICHAILIDIS N, CHRISTODOULOU P, KALAITZOGLOU I, GOUVAS G. BERIS A. Ipsilateral atrophy of paraspinal and psoas muscle in unilateral back pain patients with monosegmental degenerative disc disease. $\mathrm{Br} \mathrm{J}$ Radiol. 2011;84:709-13.

37. BARKER KL, SHAMLEY DR. JACKSON D. Changes in the cross-sectional area of multifidus and psoas in patients with unilateral back pain: the relationship to pain and disability. Spine (Phila Pa 1976). 2004;29:E515-19.

38. CHAN ST, FUNG PK, NG NY, et al. Dynamic changes of elasticity, cross-sectional area, and fat infiltration of multifidus at different postures in men with chronic low back pain. SPINE J. 2012;12:381-88.

39. YANIK B, KEYIK B. CONKBAYIR I. Fatty degeneration of multifidus muscle in patients with chronic low back pain and in asymptomatic volunteers: quantification with chemical shift magnetic resonance imaging. SKELETAL RADIOL. 2013;42:771-78.

40. MENGIARDI B, SCHMID MR. BOOS N, et al. Fat content of lumbar paraspinal muscles in patients with chronic low back pain and in asymptomatic volunteers: quantification with MR spectroscopy. RADIOLOGY. 2006;240:786-92.

41. MANNION AF, CONNOLLY B, WOOD K. DOLAN P. The use of surface EMG power spectral analysis in the evaluation of back muscle function. J Rehabil Res Dev. 1997;34:427-39.

42. GOUBERT D, OOSTERWIJCK JV. MEEUS M, DANNEELS L. Structural Changes of Lumbar Muscles in Non-specific Low Back Pain: A Systematic Review. PAIN PHYSICIAN. 2016;19:E985-1000.

43. KALICHMAN L, HODGES P, LI L, GUERMAZI A, HUNTER DJ. Changes in paraspinal muscles and their association with low back pain and spinal degeneration: CT study. EUR SPINE J. 2010;19:1136-44.

44. MCLOUGHLIN RF, D'ARCY EM, BRITTAIN MM, FITZGERALD O, MASTERSON JB. The significance of fat and muscle areas in the lumbar paraspinal space: a CT study. J Comput Assist Tomogr. 1994;18:275-78.

45. PAALANNE N, NIINIMAKI J, KARPPINEN J, et al. Assessment of association between low back pain and paraspinal muscle atrophy using opposed-phase magnetic resonance imaging: a population-based study among young adults. Spine (Phila Pa 1976). 2011;36:1961-68.

46. SCOTT IR, VAUGHAN AR. HALL J. Swiss ball enhances lumbar multifidus activity in chronic low back pain. PHYS THER SPORT. 2015;16:40-4.

47. YARJANIAN JA, FETZER A, YAMAKAWA KS, TONG HC. SMUCK M, HAIG A. Correlation of paraspinal atrophy and denervation in back pain and spinal stenosis relative to asymptomatic controls. PM R. 2013;5:39-44.

48. RANTANEN J, HURME M. FALCK B, et al. The lumbar multifidus muscle five years after surgery for a lumbar intervertebral disc herniation. Spine (Phila Pa 1976). 1993;18:568-74.

49. KOPPENHAVER SL, HEBERT JJ, PARENT EC, FRITZ JM. Rehabilitative ultrasound imaging is a valid measure of trunk muscle size and activation during most isometric sub-maximal contractions: a systematic review. Aust J Physiother. 2009;55:153-69.

50. HERBERT RD, MOSELEY AM, BUTLER JE, GANDEVIA SC. Change in length of relaxed muscle fascicles and tendons with knee and ankle movement in humans. J Physiol. 2002;539:637-45. 
51. HODGES PW, PENGEL LH, HERBERT RD, GANDEVIA SC. Measurement of muscle contraction with ultrasound imaging. MUSCLE NERVE. 2003;27:682-92.

52. KOPPENHAVER S, KNISS J, LILLEY D, et al. Reliability of ultrasound shear-wave elastography in assessing low back musculature elasticity in asymptomatic individuals. J Electromyogr Kinesiol. 2018;39:49-57.

53. CHOPP-HURLEY JN, PROPHET C, THISTLE B, POLLICE J. MALY MR. Scapular Muscle Activity During Static Yoga Postures. J Orthop Sports Phys Ther. 2018;48:504-09.

\section{Figures}

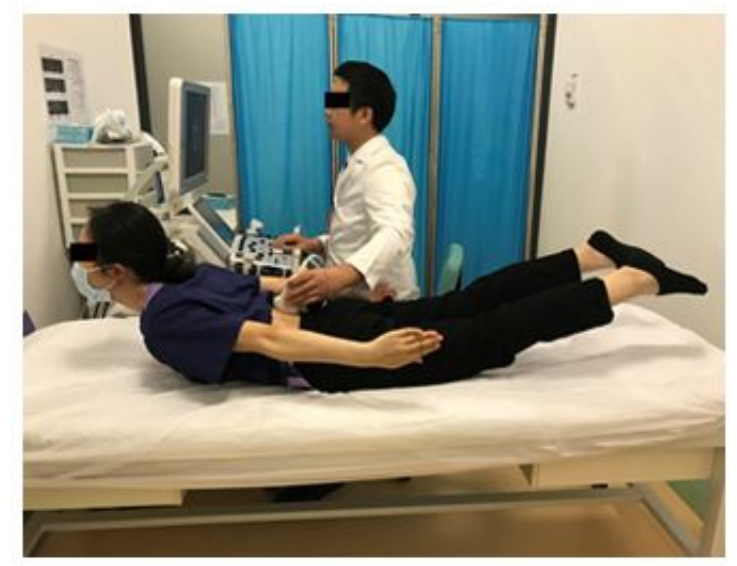

\section{Figure 1}

The head is lifted upward as much as possible, and both the upper limbs and lower limbs are stretched out from the bed surface. The lower abdomen is in contact with the bed surface to act as the fulcrum. The angle of the lower limbs and fulcrum and the angle of the upper body and fulcrum are close to $30^{\circ}$. The whole body is bent like an inverted arch. 

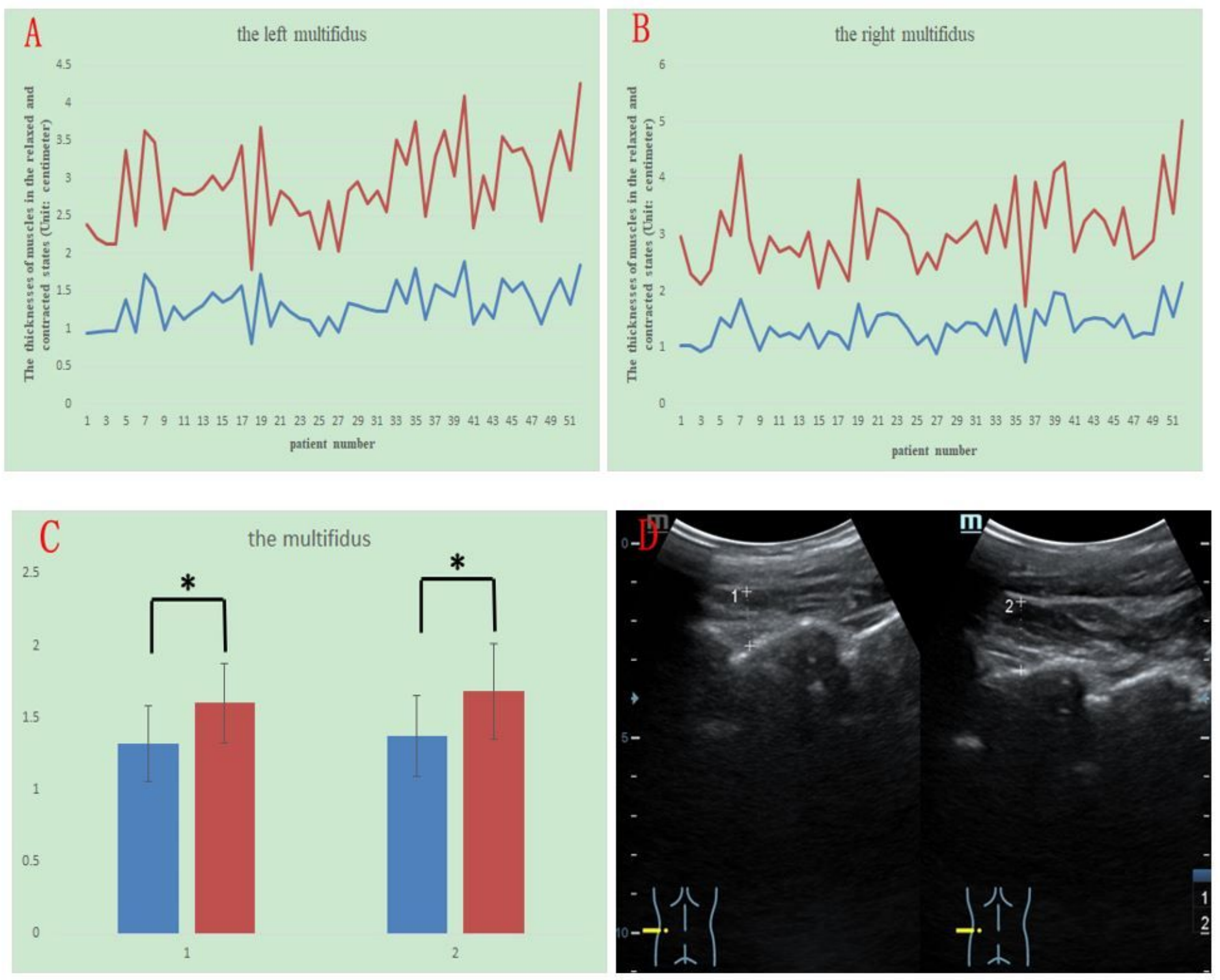

\section{Figure 2}

The thicknesses of the left(Fig $2 \mathrm{~A})$ and $\operatorname{right}($ Fig $2 \mathrm{~B})$ multifidus in the resting $\varangle$ blue line $\mathbb{Z}$ and contracted conditions (red line); Comparison of the thicknesses in the resting $\varangle$ blue column\and contracted conditions (red column), group 1 is right, group 2 is left(Fig 2 C); the sonogram of the multifidus: left shows relaxed state and right shows contracted state. (Fig 2 D) 

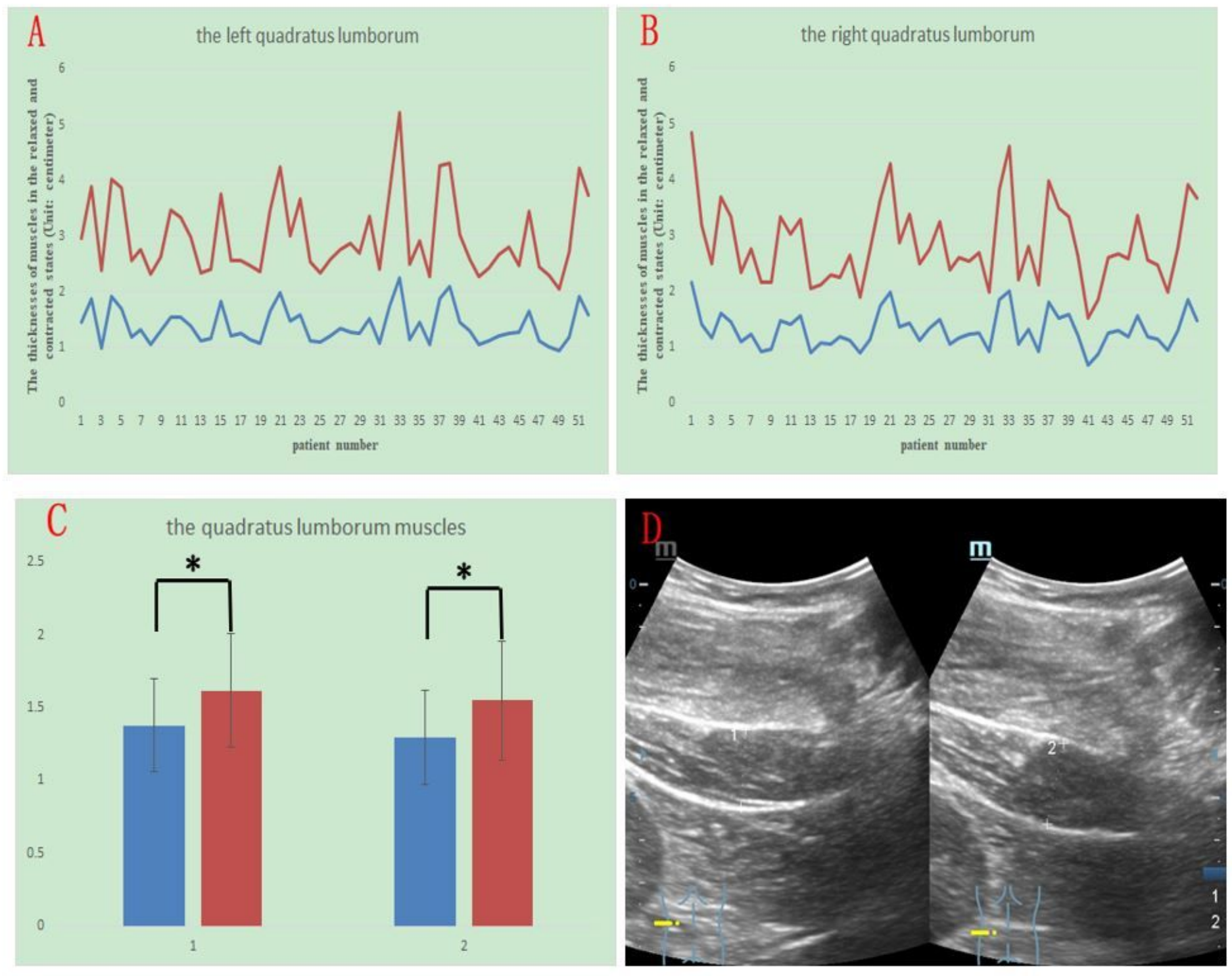

\section{Figure 3}

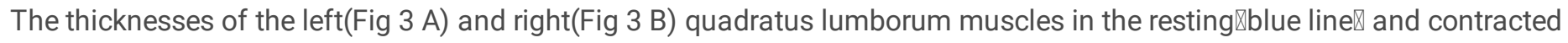
conditions (red line); Comparison of the thicknesses in the resting $₫$ blue column $₫$ and contracted conditions (red column), group 1 is right, group 2 is left(Fig $3 \mathrm{C}$ ); the sonogram of the quadratus lumborum: left shows relaxed state and right shows contracted state. (Fig 3 D) 

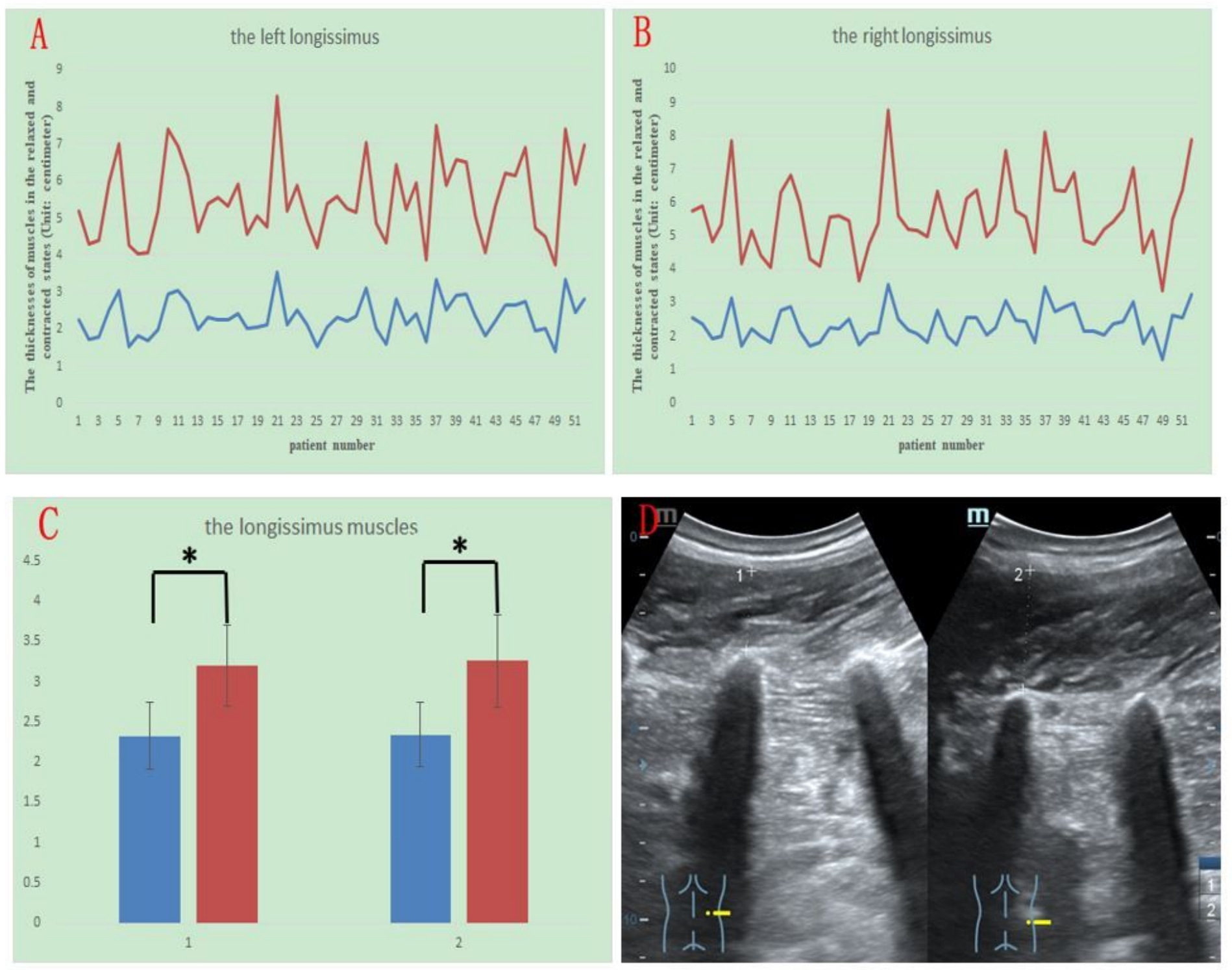

\section{Figure 4}

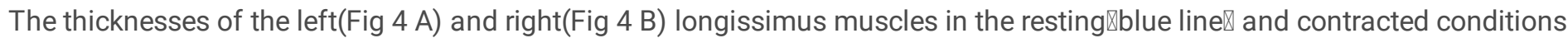
(red line); Comparison of the thicknesses in the resting $₫$ blue column囚and contracted conditions (red column), group 1 is right, group 2 is left(Fig 4 C); the sonogram of the longissimus: left shows relaxed state and right shows contracted state. (Fig 4 D) 

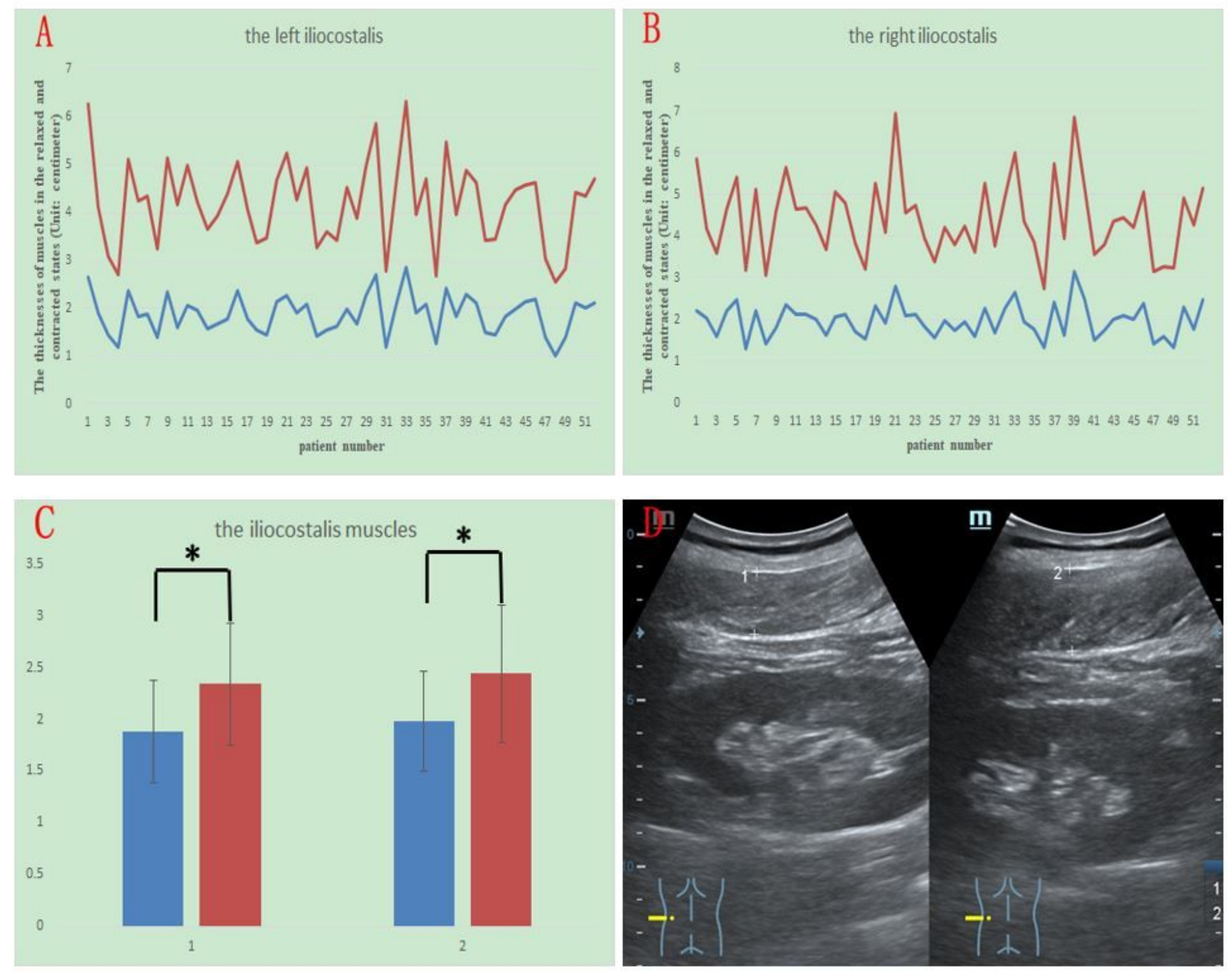

\section{Figure 5}

The thicknesses of the left(Fig $5 \mathrm{~A}$ ) and right(Fig 5 B) iliocostalis muscles in the resting (blue line) and contracted conditions (red line); Comparison of the thicknesses in the resting (blue column) and contracted conditions (red column), group 1 is right, group 2 is left(Fig 5 C); the sonogram of the iliocostalis: left shows relaxed state and right shows contracted state. (Fig 5 D) 